Identification of Sour Orange

\section{Accessions and Evaluation of Their Genetic Variability by Molecular Marker Analyses}

\author{
Mirko Siragusa, Fabio De Pasquale, Loredana Abbate, and \\ Nicasio Tusa ${ }^{1}$ \\ Institute of Plants Genetic (Section Palermo), National Council of Researches, \\ Corso Calatafimi 414, I-90129 Palermo, Italy
}

Additional index words. Citrus aurantium, Citrus rootstock, ISSR, RAPD, genetic variability, Dice's coefficient, UPGMA

\begin{abstract}
A collection of 18 accessions of sour orange (Citrus aurantium L.) coming from Sicily and other countries was investigated by two polymerase chain reaction (PCR)-based DNA marker technologies. Ten inter-simple sequence repeat (ISSR) primers and fifteen randomly amplified polymorphic DNA (RAPD) primers were used to identify and to evaluate the genetic variability and relationship of accessions. A total of 111 ISSR and 145 RAPD amplified fragments were used to estimate the Dice's coefficient of similarity for cluster analysis using a unweighted pair-group method using an arithmetic averaging (UPGMA) algorithm. The genetic relationships identified using ISSR and RAPD markers were highly concordant, such that the correlation between ISSR and RAPD genetic distance (GD) estimates was $r=0.93$. The ISSR and RAPD analysis of 18 sour orange accessions found a high grade of genetic diversity in foreign accessions, while a low variability was detected in local accessions. Sicilian accessions could be grouped in two distinct clusters, including indistinctly plants from three origin regions. Some markers could be linked to the different growing areas. The ISSR and RAPD molecular reference system seems to be suitable for a fine identification of tightly related plants and the obtained results can form the basis for future setting up of Citrus rootstock genetic improvement projects.
\end{abstract}

Sour orange (Citrus aurantium L., $2 \mathrm{n}=2 \mathrm{x}$ $=18)$ is one of the most widely used Citrus rootstocks in the world. Despite its decreasing cultivation because of spreading citrus tristeza virus (CTV), sour orange is still cultivated in many countries, in particular in the Mediterranean Sea coasts. Its importance is due mainly to its capability of growing in calcareous and saline soil and being tolerant to several serious Citrus diseases (such as phytophthora, exocortis, and xyloporosis viroid and blight). Furthermore, sour orange guarantees consistent yields, good fruit quality, and ability to import cold hardiness to the scion (Castle, 1987). In nurseries, sour orange cultivation is represented by local populations seed-propagated and maintained overgenerations by selection based on morphological traits (Herrero et al., 1996). As with other polyembryonic Citrus species, seedling populations of sour orange are genetically quite uniform because they arise from apomictic seed through nucellar embryony (Castle, 1987; Esan, 1973; Xiang and Roose, 1988), allowing clonal propagation. However, sour orange produces seeds that contain both nucellar and zygotic (sexual) embryos, and

Received for publication 7 June 2005. Accepted for publication 26 Sept. 2005. This research was supported by research grant of Scrigno Project (Develop and Characterization of Genetic Resources Native in Market Gardening) from Ministry of University and Research (MIUR).

${ }^{1}$ Corresponding author; e-mail nicasio.tusa@igv. cnr.it. therefore uniformity is almost complete. Off-type seedlings are generally eliminated by nurserymen, but zygotic seedlings are sometimes difficult to identify and they could develop plants with very different agronomic traits. Currently, in southern Italy, there are several sour orange populations with interesting agronomical traits, but no information is available about their variability, and no type characterization has been done yet. Because the rootstock can greatly affect performance of trees budded onto them (Roose and Traugh, 1988), an improved understanding of sour orange genetic diversity is desirable to select lines suitable for increasing the productivity of Citrus cultivations. It also would permit to isolate, within the best local selections, individuals amenable for setting up new breeding programmes for genetic improvement. These breeding programmes aim to constitute mainly new CTV-resistant hybrid rootstocks having the same good qualities of sour orange (Grosser et al., 2004).

Polymerase chain reaction (PCR)-based DNA marker technologies have represented a useful tool to characterize closely related plants (Barcaccia et al., 2003; Imazio et al., 2002) and to evaluate the genetic homogeneity and purity, respectively, of inbreeds and hybrids (Bellamy et al., 1996; Scarano et al., 2002). They were also used to investigate the phylogenetic relationship between plants and populations belonging to the same genus (Burstin et al., 2001; Rossetto et al., 2002).
In particular, PCR methods using arbitrary primers have become very popular among researchers since 1990 (Williams et al., 1990), as they do not require any information about DNAsequences. Of these techniques, randomly amplified polymorphic DNA (RAPD), using 10 base pairs random primers, is the most widely applied (Lanham et al., 1995; Mailer et al., 1994; Stiles et al., 1993), principally due to the easiness of the procedure and the very low amount of DNA required for analysis. In Citrus, RAPD markers have been used previously for studies about genetic diversity (Coletta Filho et al., 1998), hybrid and mutant identification (Deng etal., 1995; Elisiàrio etal., 1999), mapping (Cai et al., 1994), and linkage analysis (Cheng and Roose, 1995; Gmitter et al., 1996; Ling et al., 2000).

Inter-simple sequence repeat (ISSR) technique also uses arbitrary primers composed of a microsatellite sequence repeated in tandem (core) and a flanking sequence of two to four degenerate nucleotides (anchor). Because ISSR primers require high-annealing temperature, this technique guarantees high reliability and repeatability, in addition to cost- and time-effectiveness (Fang and Roose, 1997), especially if compared with RAPD. A few genetic studies using ISSR markers have been carried out on Citrus and Citrus-related species mainly to characterize closely related commercial varieties (Fang et al., 1997; Fang and Roose, 1997), experimental somatic hybrids (Scarano et al., 2002), and to discriminate zygotic and nucellar plants (Lambardi et al., 2004).

In the present study, phenotypically diverse sour orange accessions collected from different parts of Sicily and some foreign countries were analysed by RAPD and ISSR methods to detect genetic polymorphisms useful for setting up a molecular reference system that would allow a precise identification. This information, with morphological and phenological descriptors, could be useful for assessing the basis of breeding programmes aimed at the genetic improvement of sour orange. Data obtained from this study may also be used to provide useful information about genetic relationships among the accessions examined.

\section{Materials and Methods}

Plant materials and DNA extraction. A total of 18 accessions of Citrus aurantium L. including 15 Sicilian accessions and three foreign clones were used in the investigation. Plants different for morphological and physiological traits (Tusa et al., 1979) were collected from several sites located in the three major Citrus diffusion areas of Sicily: northwest (province of Palermo), northeast (province of Messina), and southeast (province of Siracusa-Ragusa). They were introduced in the germplasm collection in the Lascari field station $\left(38^{\circ} \mathrm{N}, 14^{\circ} \mathrm{E}\right)$. The Sicilian accessions were 'Barcellona 1' (BC1), 'Barcellona 2' (BC2), 'Barcellona 3' (BC3), 'Palermo 1'(PA1), 'Palermo 2'(PA2), 'Palermo 3' (PA3), 'Palermo 4' (PA4), 'Siracusa' (SR), 'Noto 1' (NT1), 'Noto 2' (NT2), 'Rosolini' (RSL), 'Ispica 1' (IS1), 'Ispica 2' (IS2), 'Scoglitti'(SCO) and 'Campofelice'(CM), according 


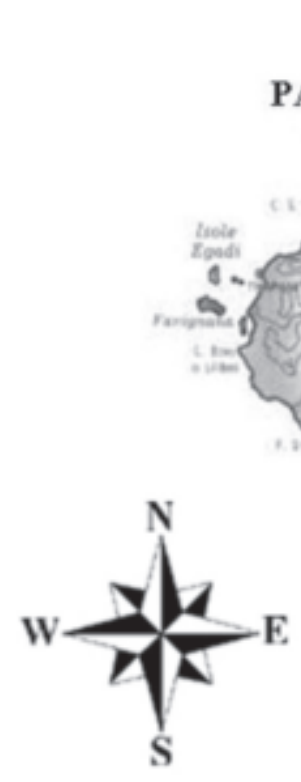

1: 1800000

Fig. 1. Localisation of the 15 Sicilian sour orange accessions used in this study. Most of the plants are concentred in three growing areas. Northwest (province of Palermo): 'Palermo 1' (PA1); 'Palermo 2' (PA2); 'Palermo 3' (PA3); 'Palermo 4' (PA4). Northeast (province of Messina): 'Barcellona 1' (BC1); 'Barcellona 2' (BC2); 'Barcellona 3' (BC3). Southeast (province of Siracusa-Ragusa): 'Noto 1'(NT1); 'Noto 2' (NT2); 'Ispica 1' (IS1); 'Ispica 2' (IS2); 'Scoglitti' (SCO); 'Siracusa' (SR); 'Rosolini' (RSL) The accession 'Campofelice' (CM), was found in a intermediate localization between Palermo and Messina areas.

to their origins. Figure 1 shows the localisation of the sites of the Sicilian accessions: 'Palermo 1', 'Palermo 2', 'Palermo 3', and 'Palermo 4' were located in the province of Palermo; 'Barcellona 1', 'Barcellona 2', and 'Barcellona 3' in province of Messina; 'Siracusa', 'Noto 1', 'Noto 2', 'Rosolini', 'Ispica 1', 'Ispica 2', and 'Scoglitti' in province of Siracusa-Ragusa. The accession 'Campofelice' (CM) was found in a intermediate localization between Palermo and Messina areas.

The three foreign clones were selected for their interesting agronomical characters. The clone 'Argentina' (ARG) is a typical Citrus rootstock of Argentina. The clone 'Smooth flat Seville'(SFS), reported also as 'Australian sour orange', is a possible sour orange hybrid less susceptible to CTV (Castle, 1987). The clone reported as 'Gou Tou' (GOU) is a CTV-resistant Chinese selection (Castle, 1987; Garnsey, 1992). The method used to isolate genomic DNA from leaves was as described by Doyle and Doyle (1987). The leaves were collected from mature trees present in the germplasm collection and they were carefully washed, as advised to avoid insects and fungal contaminations (Fang and Roose, 1997), frozen in liquid nitrogen and stored at $-80{ }^{\circ} \mathrm{C}$. The samples were ground in a mortar with liquid nitrogen. DNA was quantified by measuring $\mathrm{OD}_{2} 60$ as described by Sambrook et al. (1989) and diluted for PCR to $5 \mathrm{ng} \cdot \mu \mathrm{L}^{-1}$.

ISSR analysis. A total of 10 primers-i.e., $(\mathrm{AC})_{8} \mathrm{YG},(\mathrm{AG})_{8} \mathrm{YC},(\mathrm{AC})_{8} \mathrm{YA},(\mathrm{AC})_{8} \mathrm{YT}$, (AG) ${ }_{8} \mathrm{YT},(\mathrm{GT})_{8} \mathrm{YG},(\mathrm{TCC})_{5} \mathrm{RY},(\mathrm{GA})_{8} \mathrm{YC}$, $(\mathrm{CA})_{8} \mathrm{RG}$, and $(\mathrm{GA})_{8} \mathrm{YG}$ (reported by Fang and Roose, 1997) — were used to amplify the DNA. The primers were purchased from Life Technologies, Gaithersburg, Md.
Each amplification was performed in a $25 \mu \mathrm{L}$ reaction volume containing $20 \mathrm{~mm}$ Tris- $\mathrm{HCl}$ ( $\mathrm{pH} 8.4$ ), $50 \mathrm{~mm} \mathrm{KCl,} 2 \mathrm{~mm} \mathrm{MgCl}$, $800 \mu \mathrm{M}$ dNTP (dATP:dTTP:dCTP:dGTP in $1: 1: 1: 1$ ratio), $0.5 \mu \mathrm{M}$ of each primer, $1 \mathrm{U}$ of Platinum Taq polymerase (Life Technologies) and $30 \mathrm{ng}$ of template DNA. The amplification was performed in a MJ Research thermocycler (Genenco) equipped with a Hot Bonnet under the following cycle program: initial denaturation step for 4 min at $94{ }^{\circ} \mathrm{C}$, followed by 36 cycles at $94^{\circ} \mathrm{C}$ for $30 \mathrm{~s}$ (denaturation), $50{ }^{\circ} \mathrm{C}$ for $45 \mathrm{~s}$ (annealing) and $72{ }^{\circ} \mathrm{C}$ for 120 $\mathrm{s}$ (extension), followed by a final extension step at $72{ }^{\circ} \mathrm{C}$ for $7 \mathrm{~min}$. PCR-amplified DNA fragments were separated on a $1.5 \%$ agarose gel containing $1 \times$ TBE $(45 \mathrm{~mm}$ Tris-borate, 1 mM EDTA) and $0.5 \mu \mathrm{g} \cdot \mathrm{mL}^{-1}$ aqueous solution of ethidium bromide. About $25 \mu \mathrm{L}$ of reaction products (with an adequate amount of loading buffer) were loaded and the gel was run for 4 $\mathrm{h}$ at $100 \mathrm{~V}$. The gel was then visualized with a UV transilluminator at $300 \mathrm{~nm}$. To confirm the reproducibility of the banding patterns, the PCR experiments were repeated three times.

RAPD analysis. Fifteen arbitrary decamer primers-i.e., OPH04, OPAT14, OPH15, OPM04, OPO14, and OPN14 (reported by Coletta Filho, 1998) and UBC219, UBC234, UBC237, UBC239, UBC247, UBC251, UBC264, UBC266, and UBC272 (reported by Wang, 1999) were used for the amplification of DNA sequences. The primers were purchased from Life Technologies, Gaithersburg, Md.

DNA amplification reactions were performed in a volume of $25 \mu \mathrm{L}$ with $20 \mathrm{mM}$ Tris- $\mathrm{HCl}$ (pH 8.4), $50 \mathrm{~mm} \mathrm{KCl,} 3 \mathrm{~mm} \mathrm{MgCl}_{2}$, $800 \mu \mathrm{M}$ dNTP, $0.4 \mu \mathrm{M}$ of each primer, $1 \mathrm{U}$ of Platinum Taq polymerase (Life Technologies) and $30 \mathrm{ng}$ of template DNA. The amplification was performed in a MJ Research thermocycler (Genenco) equipped with a Hot Bonnet under the following cycle program: initial denaturation step for $90 \mathrm{~s}$ at $94{ }^{\circ} \mathrm{C}$, followed by 40 cycles at $94^{\circ} \mathrm{C}$ for $1 \mathrm{~min}$ (denaturation), $35^{\circ} \mathrm{C}$ for $2 \mathrm{~min}$ (annealing) and $72{ }^{\circ} \mathrm{C}$ for 2 min (extension), followed by a final extension step at $72{ }^{\circ} \mathrm{C}$ for $10 \mathrm{~min}$. PCR-amplified DNA fragments were visualized as described above. To confirm the reproducibility of the banding patterns, all analyses were repeated three times.

Data analysis. Amplified bands from each primer were scored as present (1) or absent (0) for all the accessions studied. Only those bands showing consistent amplification were considered; smeared and weak bands were excluded from the analysis. Dice's (1945) coefficient of similarity $\left(D_{i j}\right)$ was determined between each pair of accessions. Dice's coefficient has been recommended for the evaluation of genetic similarities when using RAPD data (Lamboy, 1994). The genetic distance (GD) between two samples was calculated as: $\mathrm{GD}=1-\mathrm{D}$... The degree of concordance between ISSR and RAPD markers was determined by visual appraisal of graphic depictions generated from the analysis of GD values and correlation analysis (Pearson rank correlation) using Microsoft Excel 2000. The estimates of similarity between accessions were then used for cluster analysis by unweighted pair group method of arithmetic average (UPGMA) (Sneath and Sokal, 1973) using the NTSYS package version 2.02 for windows (Rohlf, 1994).

Additional statistics were computed to estimate the grade of polymorphism among plants studied. The average marker allele frequency $\left(\mathrm{p}_{\mathrm{i}}\right)$ for each primer and among all primers was calculated for each single accession and among all accessions. Genetic diversity $(\mathrm{H})$ of Nei (1973) and Shannon Index (S) (Lewontin, 1972) were used to summarize the data for molecular markers and their standard deviations (St. Dev.) were indicated. The percentage of polymorphisms $(\mathrm{P})$ was given as number of polymorphic loci/ number of total loci, regardless of allele frequencies. The fixation index $\left(\mathrm{G}_{\mathrm{ST}}\right)$ was computed as proportion of genetic diversity expressed between accessions coming from different geographic regions. From this, the gene flow $(\mathrm{Nm})$ was derived and interpreted according to McDermott and McDonald (1993). All calculations and analyses were conducted using the software POPGENE version 1.31 (Yeh et al., 1999).

\section{Results}

ISSR. A total of 10 ISSR primers were used for analyzing the patterns of 18 (15 Sicilian and 3 foreign) selected sour orange accessions. These ISSR primers had been already used successfully in Citrus characterization studies by Fang and Roose (1997).

A total of 111 well-resolved band classes were observed. The amplified fragments ranged from $180 \mathrm{bp}$ [primer (GA) ${ }_{8} \mathrm{YG}$ ] to $2.3 \mathrm{~kb}$ $\left[\right.$ primer $\left.(\mathrm{CA})_{8} \mathrm{RG}\right]$ in size. The number of ISSR bands obtained for each primer varied from 7 


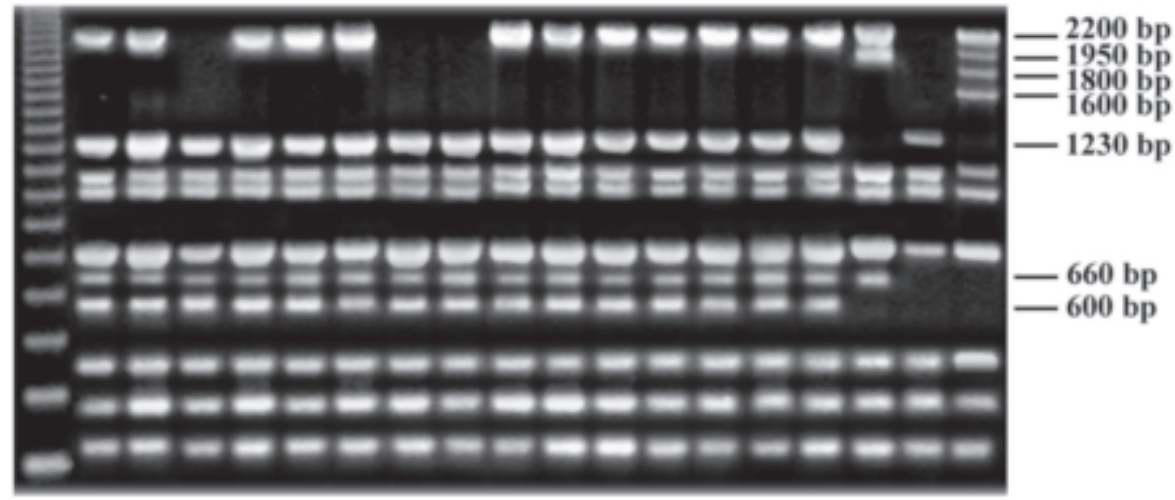

Fig. 2. Intersimple sequence repeat (ISSR) profiles amplified from DNA of sour orange accessions analysed using primer (AG) $)_{8} Y T$. M, 123-bp DNA ladder; 1, 'Barcellona 1'; 2, 'Barcellona 2'; 3, 'Palermo 1'; 4, 'Barcellona 3'; 5, 'Siracusa'; 6, 'Noto 1'; 7, 'Noto 2'; 8, 'Rosolini'; 9, 'Ispica 1'; 10, 'Ispica 2'; 11, 'Scoglitti'; 12, 'Palermo 2'; 13, 'Palermo 3'; 14, 'Palermo 4'; 15, 'Campofelice'; 16, 'Argentina'; 17, 'Smooth flat Seville'; 18, 'Gou Tou'.

[primer $(\mathrm{CA})_{8} \mathrm{RG}$ ] to 14 [primer $(\mathrm{GA})_{8} \mathrm{YC}$ ], with an average of 11 bands per primer.

All the primers screened revealed marked polymorphism in foreign plants. In particular, the ISSR primer (AC) ${ }_{8}$ YT amplified unique markers for the clones 'Argentina', 'Smooth flat Seville' and 'Gou Tou'. Six primers $\left[(\mathrm{AC})_{8} \mathrm{YG},(\mathrm{AG})_{8} \mathrm{YC},(\mathrm{AC})_{8} \mathrm{YT},(\mathrm{AG})_{8} \mathrm{YT}\right.$, (GT) ${ }_{8} \mathrm{YG},(\mathrm{CA})_{8} \mathrm{RG}$ ] were also able to identify differences in Sicilian accessions and the ISSR primer $(\mathrm{CA})_{8} \mathrm{RG}$ amplified a unique fragment for the Sicilian accession 'Ispica 1'. These data are already an indication of the presence of moderate diversity among the studied accessions. Out of 111 amplified bands, $33(P=$ 29.7\%) were polymorphic. As shown in Fig. 2, the primer $(\mathrm{AG})_{8}$ YT gave the highest number of polymorphisms (7) and high values of Nei's gene diversity $(\mathrm{H})$ were obtained for its 600 bp $(\mathrm{H}=0.483)$ and 2200-bp-long $(\mathrm{H}=0.498)$ amplified bands.

The total number of amplified fragments generated per primer had no correlation with the proportion of polymorphic bands. For example, the primers $(\mathrm{GA})_{8} \mathrm{YC}$ and $(\mathrm{AG})_{8} \mathrm{YT}$ amplified about the same number of bands (14 and 13 respectively), but the primer (GA) $\mathrm{YC}$ showed only 1 polymorphic band $(P=7.1 \%)$, whereas the primer $(\mathrm{AG})_{8} \mathrm{YT}$ revealed $7(P$ $=53.8 \%$ ).

The polymorphisms identified were used to generate the GD matrix (above the diagonal of Table 1). The average GD among Sicilian accessions was extremely low (0.017); the single values were never higher than 0.045 . The accessions 'Barcellona 3', 'Siracusa', 'Scoglitti', and 'Palermo 2' showed minimal GD values. The GDs between the foreign clone 'Argentina' and the Sicilian accessions ranged from 0.065 (with 'Palermo 1' and 'Noto 2') to 0.107 ('Ispica 1'), whereas the GDs with 'Smooth flat Seville' and 'Gou Tou' were higher ( 0.170 and 0.224 respectively). The GD between 'Smooth flat Seville' and 'Gou Tou' was lower than expected (0.111).

$R A P D$. The RAPD analysis was conducted using six RAPD primers (reported by Coletta Filho, 1998) previously used in Citrus analysis, and nine UBC RAPD primers (reported by Wang, 1999) previously used only in Vitis vinifera studies. All 15 RAPD primers produced a total of 145 well-resolved band classes, 50 of these $(P=34.5 \%)$ were polymorphic. The RAPD primers OPN14, OPH15, and UBC239 were able to amplify unique markers for the clones 'Argentina', 'Smooth flat Seville' and 'Gou Tou'. The total of the RAPD bands were used to create a GD matrix (below the diagonal of the Table 1). When ISSR and RAPD GD estimates were compared, the RAPD values average GD among Sicilian accessions was low (0.03) but almost twice than that obtained from ISSR analysis. GDs among accessions 'Barcellona 3', 'Siracusa', 'Scoglitti', and 'Palermo 2' ranged from 0.01 to 0.042 . As observed with were generally higher than those of ISSR. The
ISSR data derived GDs, the clone 'Argentina' showed GD estimates lower with the Sicilian accessions (from 0.095 to 0.055 ) than with the foreign clones 'Smooth flat Seville' and 'Gou Tou' ( 0.132 and 0.287 respectively). The GD between 'Gou Tou' and 'Smooth flat Seville' $(0.3)$ was three times higher than that obtained from ISSR analysis.

The 9UBC RAPD primers previously used in Vitis studies gave 86 band classes $(59.3 \%$ of the total RAPD bands obtained), with an average of 9.6 bands per primer. These bands ranged from $430 \mathrm{bp}$ (primer UBC 219) to $2.3 \mathrm{~kb}$ (primer UBC 219). These results are comparable to data obtained in Vitis accessions by Wang (1999). On the contrary, the capability to discriminate the accessions was lower, only 9 amplified fragments $(P=10.5 \%)$ were polymorphic and the diversity was mostly linked to foreign clones.

Best results were obtained with the 6RAPD primers chosen from Citrus characterization literature. These primers gave 59 band classes (with an average of 9.8 bands per primer), ranging from $300 \mathrm{bp}$ (primer OPN14) to $3 \mathrm{~Kb}$ (primer OPAT14). These constituted only the $40.7 \%$ of the total RAPD band classes obtained but 32 bands $(54.2 \%$ of fragments amplified from these 6 primers) were polymorphic, that is the $64 \%$ of the total polymorphic RAPD bands. In particular, as shown in Fig. 3, the primer OPH15 amplified 12 bands, out of these 9 were able to identify polymorphisms. These polymorphisms were able to discriminate tightly associated accessions. High Nei's gene diversity $(\mathrm{H})$ was obtained with the 1400 bp-long OPH04 band $(\mathrm{H}=0.498)$ and with $850 \mathrm{bp}$ and 500-bp-long fragments obtained respectively with the primers OPM04 and OPAT14 $(\mathrm{H}=0.488)$.

Genetic relationships among Citrus aurantium accessions analyzed with ISSR and $R A P D$ markers. Pair-wise comparison of GD values was used to determine the concordance between ISSR and RAPD markers. The correlation between ISSR and RAPD markers was $\operatorname{high}(r=0.93)$, and the regression line equation describing this relationship was $\mathrm{y}=0.819+$ +0.002 . Because of the concordance between markers, a joint analysis was performed using all the available marker data. Dice's similarity was used to carry out the cluster analysis and to generate a dendrogram showing the relationship among the selected accessions, as

Table 1. Matrix of genetic distances (GD) estimates calculated on the basis of intersimple sequence repeat (ISSR) (above the diagonal) and randomly amplified polymorphic DNA (RAPD) (below the diagonal) markers.

\begin{tabular}{lcccccccccccc}
\hline GD & BC1 & IS1 & SCO & PA2 & CM & PA1 & BC3 & SR & NT2 & ARG & SFS & GOU \\
\hline BC1 & --- & 0.014 & 0.015 & 0.015 & 0.000 & 0.030 & 0.025 & 0.025 & 0.030 & 0.084 & 0.130 & 0.183 \\
IS1 & 0.000 & --- & 0.029 & 0.029 & 0.014 & 0.045 & 0.029 & 0.029 & 0.045 & 0.107 & 0.143 & 0.194 \\
SCO & 0.000 & 0.000 & --- & 0.000 & 0.015 & 0.015 & 0.000 & 0.000 & 0.015 & 0.080 & 0.147 & 0.200 \\
PA2 & 0.010 & 0.010 & 0.010 & --- & 0.015 & 0.014 & 0.000 & 0.000 & 0.015 & 0.080 & 0.147 & 0.200 \\
CM & 0.020 & 0.020 & 0.020 & 0.030 & -- & 0.030 & 0.015 & 0.015 & 0.030 & 0.084 & 0.130 & 0.183 \\
PA1 & 0.042 & 0.042 & 0.042 & 0.031 & 0.061 & -- & 0.015 & 0.015 & 0.000 & 0.065 & 0.164 & 0.217 \\
BC3 & 0.042 & 0.042 & 0.042 & 0.031 & 0.061 & 0.000 & --- & 0.000 & 0.015 & 0.079 & 0.147 & 0.200 \\
SR & 0.045 & 0.032 & 0.032 & 0.042 & 0.052 & 0.032 & 0.032 & --- & 0.015 & 0.079 & 0.147 & 0.200 \\
NT2 & 0.042 & 0.042 & 0.042 & 0.031 & 0.061 & 0.022 & 0.021 & 0.011 & --- & 0.065 & 0.164 & 0.217 \\
ARG & 0.075 & 0.075 & 0.075 & 0.064 & 0.095 & 0.077 & 0.077 & 0.067 & 0.055 & --- & 0.170 & 0.224 \\
SFS & 0.109 & 0.130 & 0.130 & 0.140 & 0.149 & 0.156 & 0.156 & 0.169 & 0.178 & 0.132 & --- & 0.111 \\
GOU & 0.226 & 0.226 & 0.226 & 0.234 & 0.204 & 0.250 & 0.250 & 0.243 & 0.250 & 0.287 & 0.300 & --- \\
\hline
\end{tabular}

zThe accessions 'Barcellona 2', 'Noto 1', 'Ispica 2', 'Palermo 3', and 'Palermo 4' had the same GD values of the accession 'Barcellona 1' and have been not included in this table; the accession 'Rosolini' has been not included, having the same GD values of the accession 'Noto 2 '. 


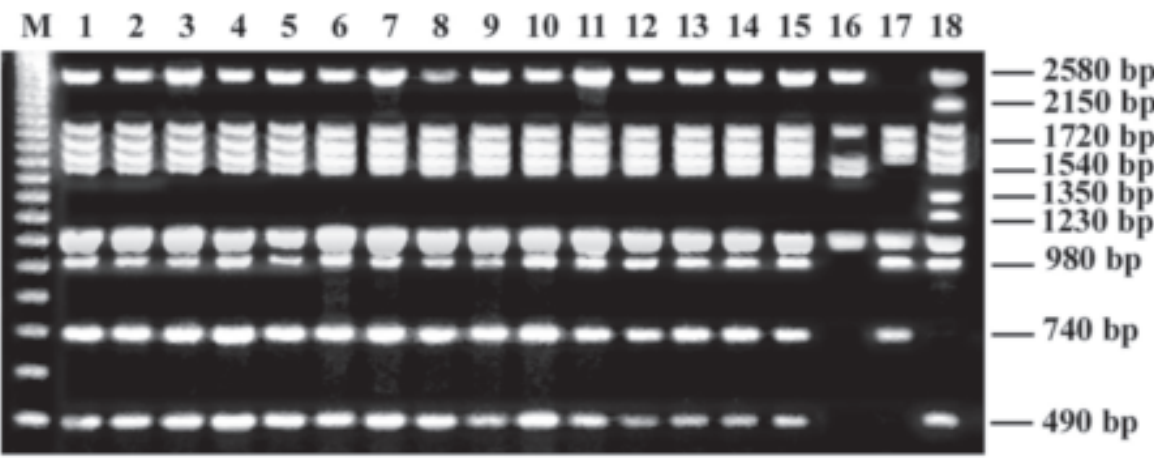

Fig. 3. Randomly amplified polymorphic DNA (RAPD) profiles amplified from DNA of sour orange accessions analysed using primer OPH15. M, 123-bp DNA ladder; 1, 'Barcellona 1'; 2, 'Barcellona 2', 3, 'Palermo 1'; 4, 'Barcellona 3'; 5, 'Siracusa'; 6, 'Noto 1'; 7, 'Noto 2'; 8, 'Rosolini'; 9, 'Ispica 1'; 10, 'Ispica 2'; 11, 'Scoglitti'; 12, 'Palermo 2'; 13, 'Palermo 3'; 14, 'Palermo 4'; 15, 'Campofelice', 16, 'Argentina'; 17, 'Smooth flat Seville'; 18, 'Gou Tou'.

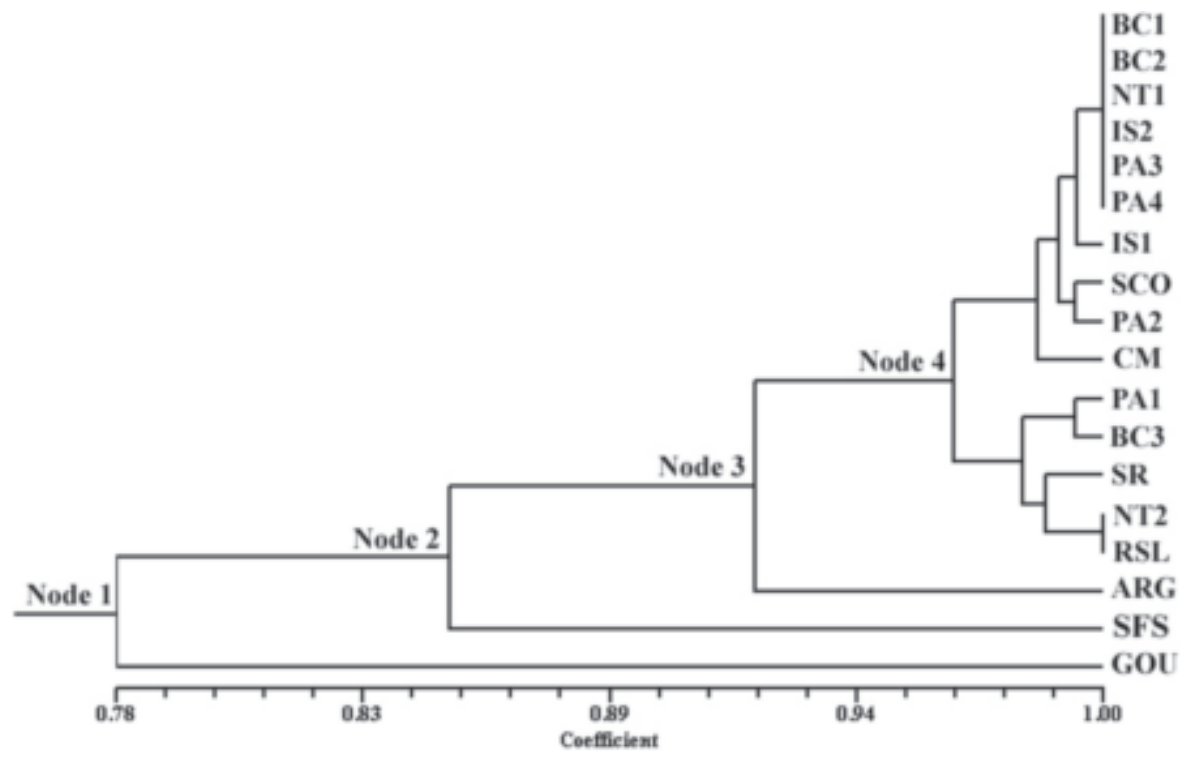

Fig. 4. The unweighted pair group method of arithmetic average (UPGMA) dendrogram of the 18 sour orange accessions obtained from Dice's coefficient similarity matrix based on intersimple sequence repeat (ISSR) and randomly amplified polymorphic DNA (RAPD) markers.

shown in Fig. 4. This dendrogram possessed four main branching nodes, with the Sicilian plants closely clustered and well separated from the foreign clones. At node 1, the 'Gou Tou' clone clustered with the remaining sour orange accessions examined, but was genetically quite distinct from them (similarity of 0.78 ). At node 2 and 3, respectively the 'Smooth flat Seville' and 'Argentina' clones could be distinguished from the Sicilian accessions, having a similarity of 0.85 and 0.92 . At node 4 , the Sicilian accessions could be clearly assigned to two groups with similarity of 0.96 . Plants belonging to these two groups came indistinctly from three different regions of Sicily: northwest (province of Palermo), northeast (province of Messina) and southeast (province of Siracusa-Ragusa).
Sicilian accessions were considered.

An analysis of gene diversity of Sicilian sour orange was carried out in accessions present in three different geographic areas (Palermo, Messina and Siracusa-Ragusa). The accession 'Campofelice' was found in an intermediate localization between two areas (Fig. 1) and its genetic profile appeared equally distant from both $(\mathrm{GDs}=0.03)$. For this reason, it was considered separately.

GD between accessions coming from Messina area and Siracusa-Ragusa area was the highest (0.011), whereas the GDs between Palermo area accessions and Messina and Siracusa-Ragusa areas accessions were respectively 0.003 and 0.008 . In Table 2 are listed some genetic diversity parameters of the three collecting geographical areas calculated separately for ISSR and RAPD analysis and their cumulative effects. Here, the higher contribution given from RAPD analysis for identification of genetic diversity appears clearly, specially for the accessions of the province of Messina. Low gene diversity was found in all three regions analyzed, with greater value in area of Palermo $\left(\mathrm{H}_{\mathrm{T}}=0.025 \pm 0.106\right)$. The fixation index $\left(\mathrm{G}_{\mathrm{ST}}=0.463\right)$ showed that as observed genetic variability could be attributed to within-area accession differences as due to differences among the three area accessions. As expected from the common propagation procedure, the estimated gene flow was extremely low $(\mathrm{Nm}=0.58)$.

Some markers could be associated with the different areas. The 2200-bp-long band amplified from ISSR primer (AG) YT was $_{8}$ found in all the accessions coming from the Messina region. The $740 \mathrm{bp}$-long fragment amplification from the RAPD primer OPN14 was tightly linked to the Siracusa-Ragusa zone accessions. The $1350 \mathrm{bp}$-long fragment from RAPD primer OPH04 was present in all the accessions of Palermo and Messina regions, whereas it was fairly uncommon in the Siracusa-Ragusa zone accessions.

\section{Discussion}

1', 'Scoglitti', and 'Palermo 2', formed a subgroup with minimal genetic differences, while the accession 'Campofelice' was the most genetically distinct. The accessions 'Siracusa', 'Noto 2', and 'Rosolini' were coming from the same region (Siracusa-Ragusa) and constituted another subgroup.

The total Nei's genetic diversity $\left(\mathrm{H}_{\mathrm{T}}\right)$ was $0.122 \pm 0.173$; it was four times lower if calculated only for the Sicilian accessions (0.029 $\pm 0.111)$. An additional measure for genetic variation was obtained by Shannon index $(S)$, a genetic diversity index suitable when dominant markers are used (Dawson et al., 1995). $S$ value was $0.191 \pm 0.249$ for all the analyzed accessions and it was $0.044 \pm 0.157$ when only
In the present study, reliable DNA finger-
prints were identified by specific patterns in different accessions of sour orange commonly employed in Sicily and in other countries.

The use of multi-locus PCR-based markers ISSR and RAPD allowed efficient differentiation of tightly linked accessions. Foreign clones could be identified by unique fragments amplified from several ISSR and RAPD primers. In RAPD primers OPN14, OPH15, and UBC239 amplified unique markers for the clones 'Argentina', 'Smooth flat Seville', and 'Gou Tou'. The ISSR primer (CA) ${ }_{8} \mathrm{RG}$ amplified a unique particular, the ISSR primer (AC) $)_{8} \mathrm{YT}$ and the

Table 2. Genetic diversity parameters calculated separately for intersimple sequence repeat (ISSR), randomly amplified polymorphic DNA (RAPD), and ISSR + RAPD analysis in the three collecting geographical areas.

\begin{tabular}{|c|c|c|c|c|c|c|c|c|c|c|}
\hline $\begin{array}{l}\text { Geographical } \\
\text { area }\end{array}$ & $\begin{array}{l}\text { Accessions } \\
\text { (no.) }\end{array}$ & \multicolumn{3}{|c|}{ Total loci } & \multicolumn{3}{|c|}{$\begin{array}{l}\text { Percent polymorphic } \\
\text { loci (no.) }\end{array}$} & \multicolumn{3}{|c|}{$\begin{array}{l}\text { Nei's gene diversity } \\
\qquad(\mathrm{H}) \pm \mathrm{SD}\end{array}$} \\
\hline Palermo & 4 & 86 & 109 & 195 & $4.65(4)$ & $5.50(6)$ & $5.13(10)$ & $0.019 \pm 0.092$ & $0.024 \pm 0.097$ & $0.025 \pm 0.106$ \\
\hline Siracusa-Ragusa & 7 & 86 & 109 & 195 & $6.98(6)$ & $5.50(6)$ & $6.15(12)$ & $0.025 \pm 0.099$ & $0.028 \pm 0.112$ & $0.023 \pm 0.096$ \\
\hline
\end{tabular}


fragment for the Sicilian accession 'Ispica 1 '. Despite the relatively low level of genetic variation, most Sicilian accessions could be uniquely identified by markers obtained from crossing analysis of two or three primers.

The great potential of the ISSR method for differentiating closely related Citrus cultivars is well documented. In particular, ISSR is the best molecular-marker system to distinguish sweet orange ( $C$. sinensis L.) cultivars and the first one that successfully differentiated certain grapefruit (C. paradisi Macf.) cultivars (Fang and Roose, 1997). Likewise, the efficiency of the RAPD method to identify tightly-linked accessions was demonstrated in many studies in several plant systems (Bhat et al., 1999; Shimada et al., 1999; Vidal et al., 1999). In Citrus, RAPD markers have been used to study genetic relationships principally in mandarin (C. reticulata Blanco) cultivars (Coletta Filho et al., 1998; Elisiàrio et al., 1999; Machado et al., 1996).

Our data confirmed that ISSR and RAPD methods are useful tools for identifying closely related accessions. Their advantages consist principally in detecting simultaneously many loci randomly distributed within the genome in a simple and cost-effective manner, requiring no previous knowledge of genome sequence as other methods, e.g., SSR.

Furthermore, the combination of ISSR and RAPD methods guarantees some additional benefits. The use of different types of molecular markers, which analyse different regions of the genome, permits a better and deeper analysis of genetic variations, as strongly recommended in several somaclonal variability studies (Martins et al., 2004; Palombi and Damiano, 2002). RAPD primers quickly scan the whole genome detecting point mutations and insertion-deletion events (Milbourne et al., 1997). ISSR markers detect the same kind of variations at hypervariable sites, such as DNA repetitive regions. In these sites, variations occur more frequently than other parts of the genome. In particular, because of a specific mechanism named DNA-polymerase slippage, mutations in lengths of repeats can happen frequently during DNA replication. These kinds of variations are detectable by ISSR analysis (Fang and Roose, 1997), but not by RAPD analysis.

The reliability of the RAPD method deserves additional discussion. Wide-scale application of molecular marker techniques by a network system is necessary to guarantee a coordinated action of laboratories requiring highly standardized and reproducible methods. While the reproducibility of RAPD technique was deeply questioned (Hansen et al., 1998; Jones et al., 1997; Karp et al., 1997), ISSR markers repeatability was confirmed in $99 \%$ of amplified fragments (Bornet and Branchard, 2001; Fang and Roose, 1997). Actually, our ISSR and RAPD markers gave a high concordance value $(r=0.93)$, allowing a joint analysis of data. Moreover, the accession-specific markers were found to be consistently stable in $98 \%$ of cases.

The molecular investigation of 18 selected sour orange accessions has also allowed the evaluation of the degree of genetic diversity reached despite of the past phenotypic-based selection carried out from nurserymen against variability (Herrero et al., 1996). Our results estimated a moderate level of genetic diversity among sour orange accessions coming from different countries. This variability was almost comparable to that identified from Coletta Filho et al. (1998) in mandarins (C. reticulata Blanco), a wide Citrus group evolved from sexual hybridization among a great number of species and intraspecific hybrids. In particular, the low similarity grade $(0.78)$ of the Chinese selection 'Gou Tou' with all the other analysed genotypes seemed to confirm its supposed natural hybrid origin (Castle et al., 1989; Müller et al., 1990), until now corroborated only by a close inspection of its fruits and isozyme profiles (H.P. Medina Filho, R. Bordignon, G.W. Müller, unpublished data; Herrero et al., 1996) and few molecular markers data (Nicolosi et al., 2000). Likewise, the similarity grade showed from 'Smooth flat Seville' (0.85) would support the hypothesis of its hybrid origin. On the contrary, a very high grade of similarity was detected in accessions located in near geographical regions. All the analysed Sicilian accessions appeared genetically quite similar $\left(\mathrm{H}_{\mathrm{T}}=0.029 \pm 0.111\right)$ but, as showed in the dendrogram, it was possible to group them into two different clusters. Also if the accessions coming from all the collecting regions were indistinctly present in both groups, a small nesting of the accessions 'Siracusa', 'Noto 2' and 'Rosolini', coming from Siracusa-Ragusa area, was noted. More interesting aspects about it come from the analysis of genetic diversity of Sicilian accessions present in the three collecting geographical areas. In fact, accessions coming from Siracusa-Ragusa area appeared more genetically different also considering GD values ( 0.011 with Messina area and 0.008 with Palermo area). On the contrary, accessions coming from Palermo and Messina areas had a lower GD value (0.003). Accessions coming from Siracusa-Ragusa area also showed the most tightly linked marker identified in this study: a 740-bp-long fragment amplified from the RAPD primer OPN14 was present in $100 \%$ of the cases, whereas it was present only in the $50 \%$ of accessions of other areas.

All our data reflects the fact that few programs of sour orange type-selection and new genotypes research have been set up. The populations of sour orange have a conserved gene pool, as confirmed by the rather low estimate of gene flow. Most of their genetic variability is therefore due to zygotic seedlings not recognized by nurserymen and propagated by mistake.

The high value of the fixation index $\left(\mathrm{G}_{\mathrm{ST}}=\right.$ 0.463 ) may be explained by taking in account three factors. First, the reproductive characteristics of sour orange: most of the seedlings develop from apomictic seed through nucellar embryony, frequently the zygotic embryos die (Xiang and Roose, 1988). Second, the lack of breeding programs keeps genetic complements apart. Third, the conservative selection criteria of offspring and mother plants to be used for seed production applied by nurserymen does not support gene exchange.
In conclusion, the molecular investigation carried out in this study allowed an evaluation of the degree of genetic differentiation reached from local and foreign sour orange accessions. The analysis of sour orange genetic variability and the set-up of a fine molecular characterization system can form the basis for future genetic breeding programs aiming to develop new and improved Citrus rootstocks. The combination of ISSR and RAPD methods has proven to be a powerful tool to separate closely related accessions and we propose it as a suitable system for evaluation of genetic diversity in plants.

\section{Literature cited}

Bhat, K.V., P.P. Babreker, and S. Lakhanpaul. 1999. Study of genetic diversity in Indian and exotic sesame (Sesamum indicum L.) germplasm using random amplified polymorphic DNA (RAPD) markers. Euphytica 110:143-147.

Barcaccia, G., L. Pallottini, M. Soattin, R. Lazzarin, P. Parrini, and M. Lucchin. 2003. Genomic DNA fingerprints as a tool for identifying cultivated types of radicchio (Cichorium intybus L.) from Veneto, Italy. Plant Breed. 122:178-183.

Bellamy, A., F. Vedel, and H. Bannerot. 1996. Varietal identification in Cichorium intibus L. and determination of genetic purity of $F_{1}$ hybrid seed sample, based on RAPD marker. Plant Breed. 115:128-132.

Bornet, B. and M. Branchard. 2001. Nonanchored Inter simple Sequence Repeat (ISSR) Markers: Reproducible and Specific Tools for Genome Fingerprinting. Plant Mol. Biol. Rpt. 19:209-215.

Burstin, J., G. Deniot, J. Potier, C. Weinachter, G. Aubert, and A. Baranger. 2001. Microsatellite polymorphism in Pisum sativum. Plant Breed. 120:311-317.

Cai, Q., C.L. Guy, and G.A. Moore. 1994. Extension of the linkage map in Citrus using random amplified polymorphic DNA(RAPD) markers and RFLP mapping of cold-acclimation-responsive loci. Theor. Appl. Genet. 89:604-614.

Castle, W.S. 1987. Citrus rootstock, p. 361-399. In: R.C. Rom and R.F. Carlson (eds.). Rootstock for Fruit Crops. Wiley, New York.

Castle, W.S., D.P.H. Tucker,A.H. Krezdorn, and C.O. Youtsey. 1989. Rootstock selection: The first step to success, p. 47-48. In: Cooperative Extension Service, rootstocks for Florida citrus. Univ. Fla. Inst. Food Agr. Sci., Gainesville.

Cheng, F.S. and M.L. Roose. 1995. Origin and inheritance of dwarfing by the Citrus rootstock and Poncirus trifoliata "Flying Dragon". J.Amer. Soc. Hort. Sci. 120:286-291.

Coletta Filho, H.D., M.A. Machado, M.L.P.N. Targon, M.C.P.Q.D.G. Moreira, and J. Pompeu, Jr. 1998. Analysis of the genetic diversity among mandarins (Citrus spp.) using RAPD markers. Euphytica 102:133-139.

Dawson, I.K., A.J. Simons, R. Waugh, and W. Powell. 1995. Diversity and genetic differentiation among subpopulations of Gliricidia sepium revealed by PCR-based assays. Heredity 75:10-18.

Deng, Z.N., A. Gentile, E. Nicolosi, A. Vardi, and E. Tribulato. 1995. Identification of in vivo and in vitro lemon mutants by RAPD markers. J. Hort. Sci. 70:117-125.

Dice, L.R. 1945. Measures of the amount of ecologic association between species. Ecology 26:297-302.

Doyle, J.J. and J.L. Doyle. 1987. A rapid DNA isolation procedure from small quantities of fresh leaf tissue. Phytochem. Bull. 19:11-15.

Elisiàrio, P.J., E. M. Justo, and J. M. Leitao. 1999. 
Identification of mandarin hybrids by isozyme and RAPD analysis. Scientia Horticulturae 81:287-299.

Esan, E.B. 1973. A detailed study of adventive embryogenesis in the Rutaceae, p. 233-234. PhD diss. Univ. Calif., Riverside.

Fang, D.Q. and M.L. Roose. 1997. Identification of closely related Citrus cultivars with inter-simple sequence repeat markers. Theor. Appl. Genet. 95:408-417.

Fang, D.Q., M.L. Roose, R.R. Krueger, and C.T. Federici. 1997. Fingerprinting trifoliate orange germplasm accession with isozymes, RFLPs, and inter-simple sequence repeat markers. Theor. Appl. Genet. 95:211-219.

Garnsey, S.M. 1992. Tolerance of Gou Tou rootstock to severe exotic isolates of citrus tristeza virus (CTV). Proc. Fla. State Hort. Soc. 105:35-38.

Gmitter, F.G., S.Y. Xiao, S. Huang, X.L. Hu, S.M. Garnsey, and Z. Deng. 1996. A localized linkage map of the citrus tristeza virus resistance gene region. Theor. Appl. Genet. 92:688-695.

Grosser, J.W., V. Medina-Urrutia, G. Ananthakrishnan, and P. Serrano. 2004. Building a replacement sour orange rootstock: Somatic hybridisation of selected mandarin + pummelo combinations. J. Amer. Soc. Hort. Sci. 129:530-534.

Hansen M., C. Hallden, and T. Sall. 1998. Error rates and polymorphism frequencies for three RAPD protocols. Plant Mol. Biol. Rpt. 16:139-146.

Herrero, R., M.J. Asìns, E.A. Carbonell, and L. Navarro. 1996. Genetic diversity in the orange subfamily Aurantioideae. I. Intraspecies and intragenus genetic variability. Theor. Appl. Genet. 92:599-609.

Imazio, S., M. Labra, F. Grassi, M. Winfield, M. Bardini, and A. Scienza. 2002. Molecular tools for clone identification: the case of the grapevine cultivar "Traminer". Plant Breed. 121:531-535.

Jones, C. J., K. J. Edwards, S. Castiglione, M. O. Winfield, F. Sala, C. van de Wiel, G. Bredemeijer, B. Vosman, M. Matthes, A. Daly, R. Brettschneider, P. Bettini, M. Buiatti, E. Maestri, A. Malcevschi, N. Marmiroli, R. Aert, G. Volckaert, J. Rueda, R. Linacero, A. Vazquez, and A. Karp. 1997. Reproducibility testing of RAPD, AFLP and SSR markers in plants by a network of European laboratories. Mol. Breed. 3:381-390.

Karp A., S. Kresovich, K.V. Bhat, W.G. Ayada, and T. Hodgkin. 1997. Molecular tools in plant genetic resources conservation: a guide to the technologies. Intl. Plant Genet. Resour. Inst. Tech. Bul. 2.

Lambardi, M.,A. De Carlo, S. Biricolti,A.M. Puglia, G. Lombardo, M. Siragusa, and F. De Pasquale. 2004. Zygotic and nucellar embryo survival following dehydration/cryopreservation of Citrus intact seeds. CryoLetters 25:81-90.

Lamboy, W.F. 1994. Computing genetic similarity coefficients from RAPD data: The Effects of PCR Artifacts, p. 31-37. In: PCR methods and applications. Cold Spring Harbor Lab.Press, New York.

Lanham, P.G., R.M. Brennan, C. Hackett, and R.J. McNicol. 1995. RAPD fingerprinting of blackcurrant (Ribes nigrum L.) cultivars. Theor. Appl. Genet. 90:166-172.

Lewontin, R.C. 1972. The apportionment of human diversity. Evol. Biol. 6:381-398.

Ling, P., L.W. Duncan, Z. Deng, D. Dunn, X. Hu, S. Huang, and F.G. Gmitter, Jr. 2000. Inheritance of citrus nematode resistance and ist linkage with molecular markers. Theor. Appl. Gen. 100:1010-1017.

Machado, M.A., H.D. Coletta Filho, M.L.P.N. Targon, and J. Pompeu, Jr. 1996. Genetic relationship of Mediterranean mandarins Citrus deliciosa Tenore using RAPD markers. Euphytica 92:321-326.

Mailer, R.J., R. Scarth, and B. Fristensky. 1994. Discrimination among cultivars of rapeseed (Brassica napus L.) using DNA polymorphisms amplified from arbitrary primer. Theor. Appl. Genet. 87:697-704.

Martins M., D. Sarmento, and M.M. Oliveira. 2004. Genetic stability of micropropagated almond plantlets, as assessed by RAPD and ISSR markers. Plant Cell Rpt. accessed 15 Sept.

McDermott, J.M. and B.A. McDonald. 1993. Gene flow in plant pathosystems. Annu. Rev. Phytopathol. 31:353-373.

Milbourne, D., R. Meyer, J.E. Bradshaw, E. Baird, N. Bonar, J. Provan, W. Powell, and R. Waugh. 1997. Comparison of PCR-based marker system for the analysis of genetic relationships in cultivated potato. Mol. Breed 3:127-136.

Müller, G.W., A.S. Costa, and J. Pompeu Jr. 1990. Importância do porta-enxerto em relação à tristeza e outras moléstias dos citros no Brasil. Anais do I Seminário Internacional de Citros, Bebedouro, Brazil, p. 223-231.

Nei, M. 1973. Analysis of gene diversity in subdivided populations. Proc. Natl. Acad. Sci. USA 70:3321-3323.

Nicolosi, E., Z.N. Deng, A. Gentile, S. La Malfa, G. Continella, and E. Tribulato. 2000. Citrus phylogeny and genetic origin of important species as investigated by molecular markers. Theor Appl. Genet. 100: 1155-1166.

Palombi, M.A. and C. Damiano. 2002. Comparison between RAPD and SSR molecular markers in detecting genetic variation in kiwifruit (Actinidia deliciosa A. Chev). Plant Cell Rpt. 20:1061-1066.

Rohlf, F.J. 1994. NTSYS: Numerical taxonomy and multivariate analysis system version 2.02. State
Univ. New York, Stony Brook.

Roose, M.L. and S.N. Traugh. 1988. Identification and performance of Citrus trees on nucellar and zygotic rootstocks. J. Amer. Soc. Hort. Sci. 113:100-105.

Rossetto, M., J. McNally, and R.J. Henry. 2002. Evaluating the potential of SSR flanking regions for examing taxonomic relationship in the Vitaceae. Theor. Appl. Genet. 104:61-66.

Sambrook, J., E.F. Fritsch, and T. Maniatis. 1989. Molecular cloning. A laboratory manual. 2nd ed. Cold Spring Harbor Lab. Press, Cold Spring, N.Y.

Scarano, M.T., L. Abbate, S. Ferrante, S. Lucetti, and N. Tusa. 2002. ISSR-PCR technique: A useful method for characterizing new allotetraploid somatic hybrids of mandarin. Plant Cell Rpt. 20:1162-1166.

Shimada, T., H. Hayama, T. Haji, M. Yamaguchi, and M. Yoshida. 1999. Genetic diversità of plums characterized by random amplified polymorphic DNA(RAPD) analysis. Euphytica 109:143-147.

Sneath, P.H. and R.R. Sokal. 1973. Numerical taxonomy: The principles and practice of numerical classification. W.H. Freeman and Co., San Francisco, Calif.

Stiles, J.L., C. Lemme, S. Sondur, M.B. Morshidi, and R. Manshardt. 1993. Using amplified polymorphic DNA for evaluating genetic relationships among papaya cultivars. Theor. Appl. Genet. 85:697-701.

Tusa, N., F. De Pasquale, and L. Radogna. 1979. Selezione clonale dell'arancio amaro (Citrus aurantium L.). Secondo seminario di studio sul miglioramento genetico del limone. Giovinazzo.

Vidal, J.R., M. Coarer, and A. Defontaine. 1999. Genetic relationship among grapevine varieties grown in different French and Spanish regions based on RAPD markers. Euphytica 109:161-172.

Wang, Y., J. Chen, J. Lu, and O. Lamikanra. 1999. Randomly amplified polymorphic DNA analysis of Vitis species and Florida bunch grapes. Scientia Hort. 82:85-94

Williams, J.G.K., A.R. Kubelik, J.L. Kenneth, J.A. Rafalski, and S.V. Tingey. 1990. DNA polymorphisms amplified by arbitrary primers are useful as genetic markers. Nucl. Acids Res. 18:6531-6535.

Xiang, C. and M.L. Roose. 1988. Frequency and characteristics of nucellar and zygotic seedlings in 12 Citrus rootstocks. Scientia Hort. 37:47-59.

Yeh, F.C., R.C. Yang, and T. Boyle. 1999. POPGENE, Version 1.31. CIFOR and Univ. Alberta, Edmonton, Alberta, Canada. 